05

\title{
Упругие и микропластические свойства титана в различных структурных состояниях
}

\author{
() Б.К. Кардашев, ${ }^{1}$ В.И. Бетехтин, ${ }^{1}$ А.Г. Кадомцев, ${ }^{1}$ М.В. Нарыкова, ${ }^{1}$ Ю.Р. Колобов ${ }^{2}$ \\ ${ }^{1}$ Физико-технический институт им. А.Ф. Иофрфе РАН, \\ 194021 Санкт-Петербург, Россия \\ ${ }^{2}$ Институт проблем химической фризики РАН, \\ 142432 Черноголовка, Московская обл., Россия \\ e-mail: b.kardashev@mail.ioffe.ru
}

(Поступило в Редакцию 23 января 2017 г.)

Изучено поведение упругих (модуль Юнга) и микропластических свойств титана в зависимости от исходной структуры и последующей интенсивной пластической деформации, переводящей материал по размеру зерна в субмикрокристаллическое структурное состояние. Показано, что различная исходная структура металла в значительной степени предопределяет его упругие свойства после деформации.

DOI: 10.21883/JTF.2017.09.44910.2172

\section{Введение}

Широкая сфера применения титана и его сплавов стимулирует систематические исследования их механических свойств, особенно после перевода титана за счет интенсивной пластической деформации (ИПД) в высокопрочное субмикрокристаллическое, наноструктурное состояние [1-4]. Использование этого материала в медицинской технике при изготовлении имплантантов требует получения высокопрочного титана, который должен обладать низким значением модуля упругости, как можно ближе к модулю упругости костной ткани $[1,4]$.

Настоящая работа посвящена изучению упругих и микропластических свойств титана с различным состоянием структуры и составом примесей до и после ИПД.

\section{Материалы и методика исследований}

В настоящей работе были исследованы три партии титана с разным содержанием примесей. Химический состав первой партии (ВТ1-0): 0.28\% примесей, из которых $0.12 \%$ составляло железо. Партия 2 (ПТ3-В) имела 5.7\% примесей, среди которых было $3.5 \%$ алюминия и $2 \%$ ванадия. Партия 3 (Grade 4) содержала 0.78\% примесей, из которых 0.39\% было железо.

Перевод в наноструктурное состояние осуществлялся с помощью ИПД отработанным режимом винтовой и продольной прокатки [1,2].

Структурные исследования проводились методами оптической и просвечивающей растровой электронной микроскопии. Установлено, что титан ВТ1-0 (партия 1) в исходном крупнозернистом состоянии имел пластинчатые зерна размером $\sim(150 \times 10) \mu \mathrm{m}$, а также вкрапления карбида титана в границах зерен размером около $1 \mu \mathrm{m}$. После ИПД наблюдались достаточно равноосные зерна размером $\sim(250 \times 290) \mathrm{nm}$. В сплаве ПТЗ-В (партия 2) в исходном состоянии наблюдались пластинчатые зерна размером $\sim(100 \times 5) \mu \mathrm{m}$, а после ИПД слегка вытянутые зерна $\sim(350 \times 200) \mathrm{nm}$. Для партии $3($ Grade 4$)$ в исходном состоянии наблюдалась почти равноосная структура со средним размером зерна около $40 \mu \mathrm{m}$. После ИПД - равноосные зерна $\sim 250 \mathrm{~nm}$. В качестве примера на рис. 1 и 2 приведены микроструктруры исследуемых сплавов ВТ1-0 и ПТ3-В в крупнозернистом и наноструктурном состояниях.

Для измерений модуля Юнга и внутреннего трения, а также изучения микропластических свойств титана в широком диапазоне амплитуд колебательных деформаций использовалась акустическая методика - резонансный метод составного пьезоэлектрического вибратора [5]. Измерялись амплитудные зависимости модуля Юнга $E(\varepsilon)$ и логарифмического декремента $\delta(\varepsilon)$. По результатам измерений $E(\varepsilon)$ строились диаграммы микропластического деформирования $\sigma\left(\varepsilon_{d}\right)$ : здесь $\sigma=E \varepsilon$ (закон Гука), а $\varepsilon_{d}-$ нелинейная неупругая (микропластическая) деформация. Подробное описание процедуры подобных построений из экспериментальных данных можно найти в [6,7]. Здесь лишь отметим, что диаграммы $\sigma\left(\varepsilon_{d}\right)$ строились из зависимостей $E(\varepsilon)$, снятых при самом первом увеличении амплитуды $\varepsilon$ на образцах, ни разу не подвергавшихся воздействию высоких амплитуд.

Для всех партий титана до и после ИПД проводилось прецизионное измерение плотности; плотность изучалась также на образцах титана, подвергнутых после ИПД воздействию высокого (до $1.5 \mathrm{GPa}$ ) гидростатического давления $(P)$. Методика всех указанных измерений рассмотрена в [2].

\section{Экспериментальные данные: амплитудные зависимости и микропластичность}

Поликристаллические образцы титана для акустических измерений имели форму стержней с прямоугольным поперечным сечением $\sim(2 \times 4) \mathrm{mm}^{2}$ и длиной 
$a$
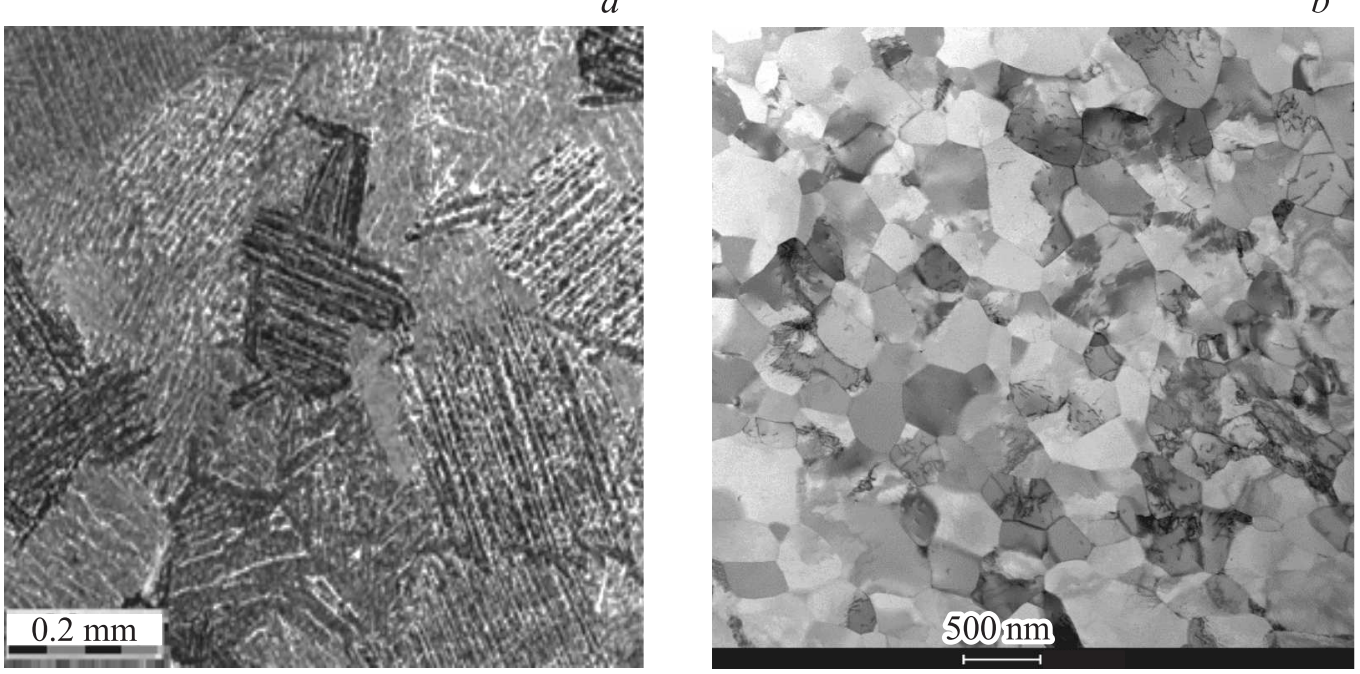

Рис. 1. Микроструктура сплава ВТ1-0 в исходном крупнозернистом $(a)$ и наноструктурированном $(b)$ состояниях.

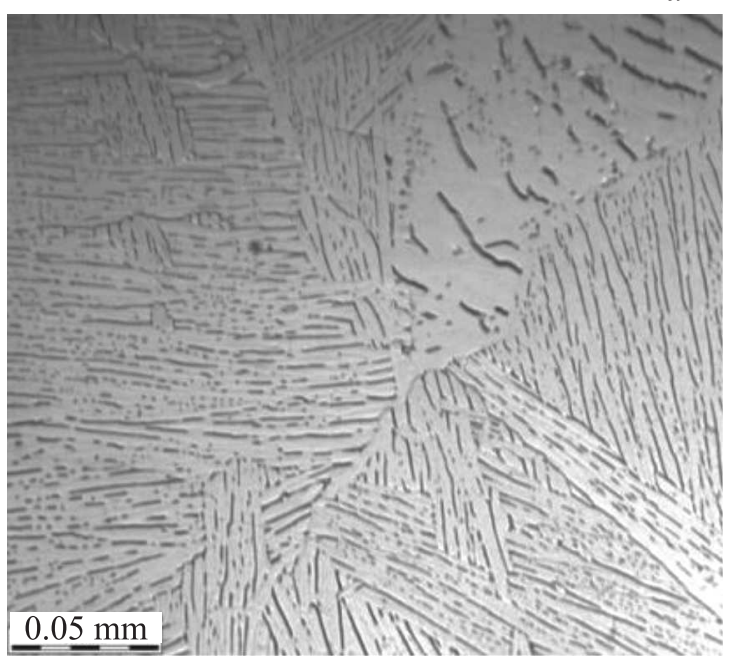

$b$

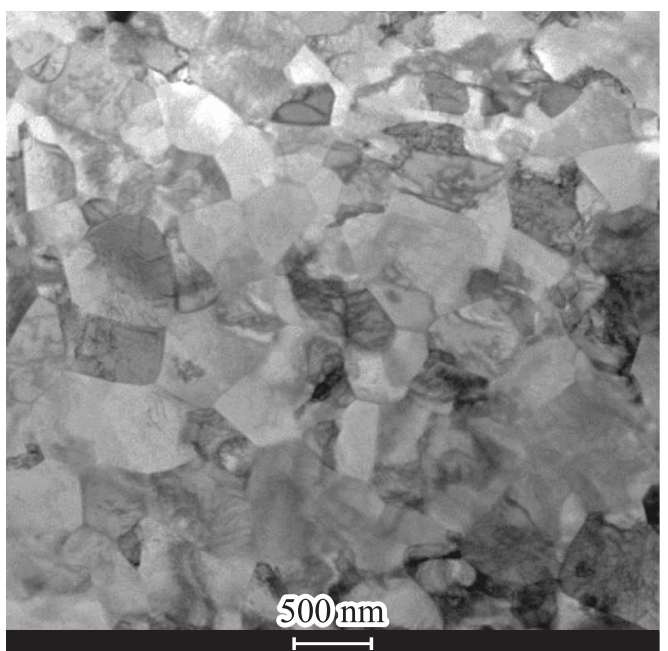

Рис. 2. Микроструктура сплава ПТЗ-И в исходном крупнозернистом (a) (продольное сечение) и наноструктурированном (b) (продольное сечение) состояниях.

около $22 \mathrm{~mm}$. Такая длина обеспечивала резонанс продольных колебаний на частотах вблизи $100 \mathrm{kHz}$ для всех образцов с разными размерами и формой зерен, как исходных, так и деформированных.

На рис. 3-5 показаны амплитудные зависимости $E(\varepsilon)$ и $\delta(\varepsilon)$, полученные на образцах титана всех трех партий. Из рисунков видно, что для исследованных материалов характерным является уменьшение модуля упругости и увеличение декремента после ИПД. При этом, как правило, наблюдается амплитудный гистерезис: кривые $E(\varepsilon)$ и $\delta(\varepsilon)$, снятые при последовательном увеличении и уменьшении амплитуды, не совпадают друг с другом. Исключение здесь составляет только наноструктурированный титан марки ВТ1-0 (рис. 3, кривые 2). В этом материале гистерезис отсутствует. Кроме того, падение модуля и рост декремента в результате ИПД здесь оказывается самым высоким: модуль Юнга уменьшается примерно на $20 \%$, а декремент вырастает более чем в 3 раза. Влияние ИПД на сплав ПТЗ-В (рис. 5) оказывается меньше (около $10 \%$ для модуля и примерно $20 \%$ для декремента). Наименее чувствительным к ИПД оказался титан марки Grade 4 (рис. 4): соответственно 1.3\% для модуля и $\sim 10 \%$ для декремента.

Что касается микропластических характеристик, в частности, условного предела микротекучести $\sigma_{y}$, то они оказались почти одинаковыми для всех исследованных нами материалов (рис. 6 и см. таблицу), кроме наноструктурированного титана ВТ1-0, который обнаружил необычное поведение диаграмм $\sigma\left(\varepsilon_{d}\right)$, представленных на рис. 7. Такого рода диаграммы являются следствием сложной зависимости $E(\varepsilon)$ у этого материала (рис. 3). Лишь при очень малых амплитудах модуль в этом 
образце слегка уменьшается и, как следствие, растет неупругая деформация $\varepsilon_{d}$ (рис. 7, $a$ ). Затем при дальнейшем увеличении $\varepsilon$ модуль Юнга заметно увеличивается.

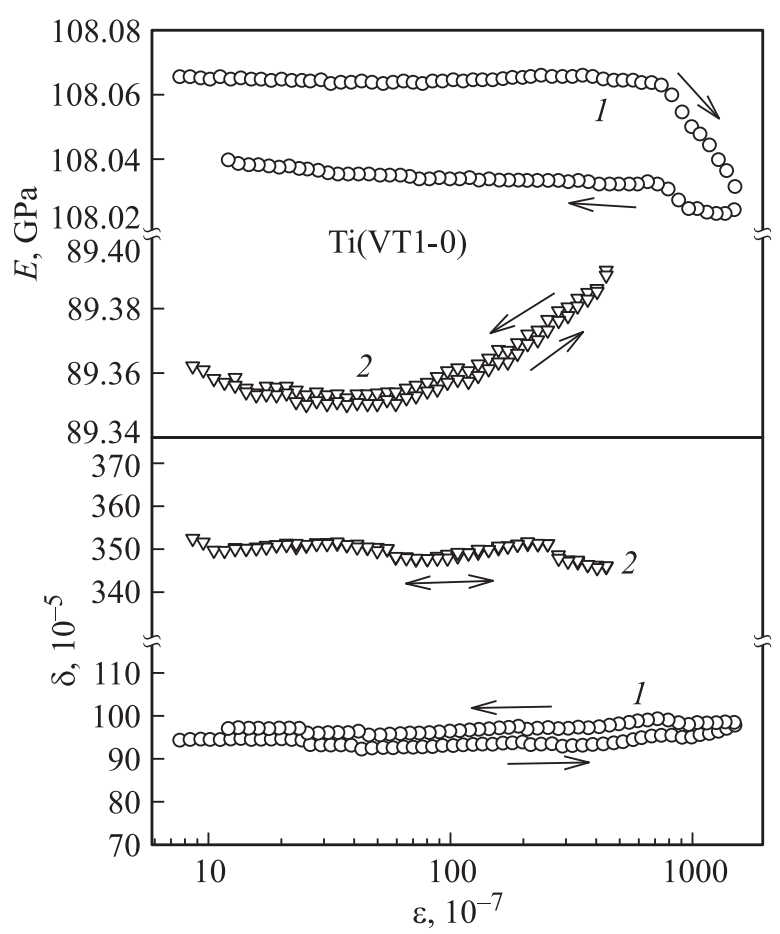

Рис. 3. Амплитудные зависимости модуля Юнга $E$ и декремента $\delta$ для образцов крупнозернистого $(1)$ и наноструктурированного (2) титана ВТ1-0.

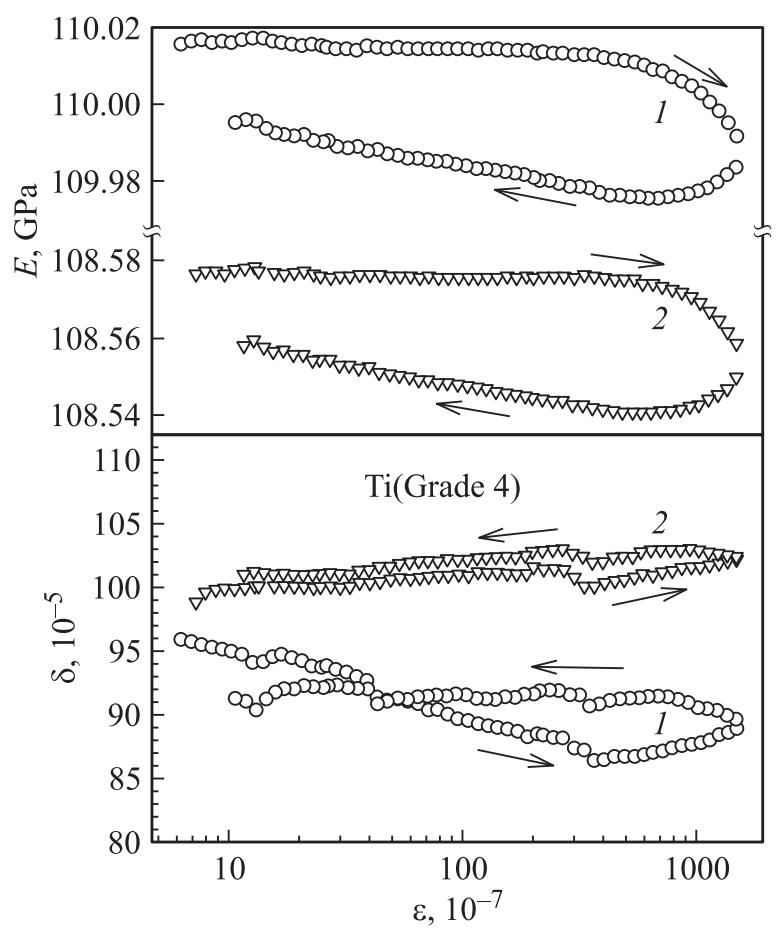

Pис. 4. Амплитудные зависимости модуля Юнга $E$ и декремента $\delta$ для образцов крупнозернистого $(1)$ и наноструктурированного (2) титана Grade 4.

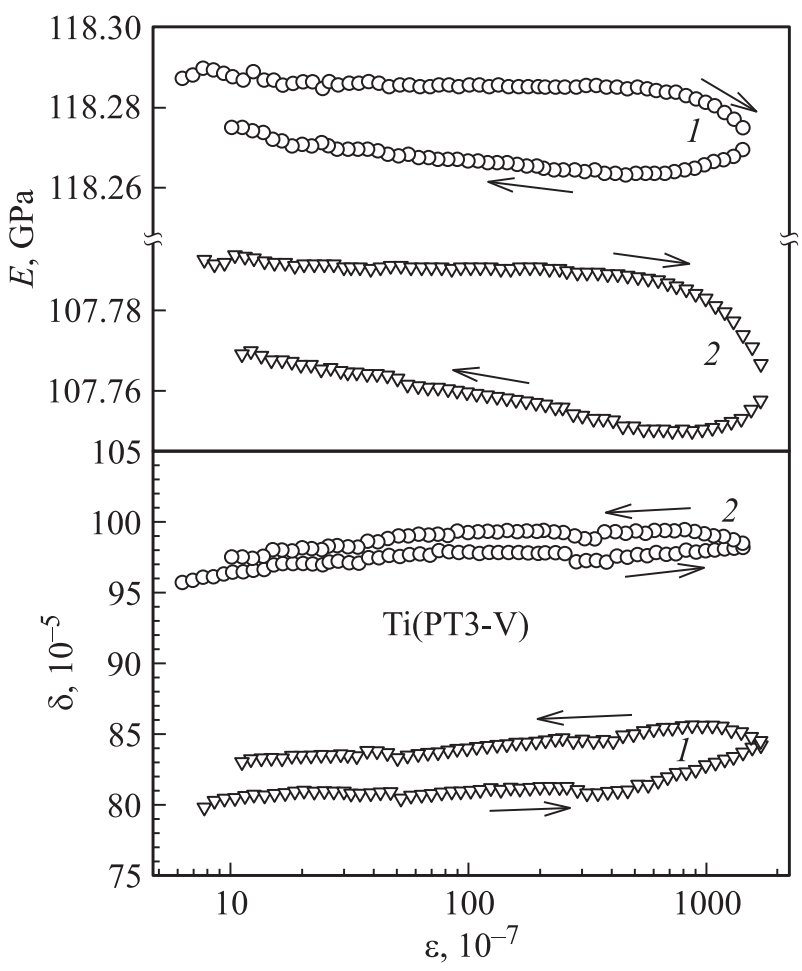

Рис. 5. Амплитудные зависимости модуля Юнга $E$ и декремента $\delta$ для образцов крупнозернистого $(1)$ и наноструктурированного (2) титана ПТ3-В.

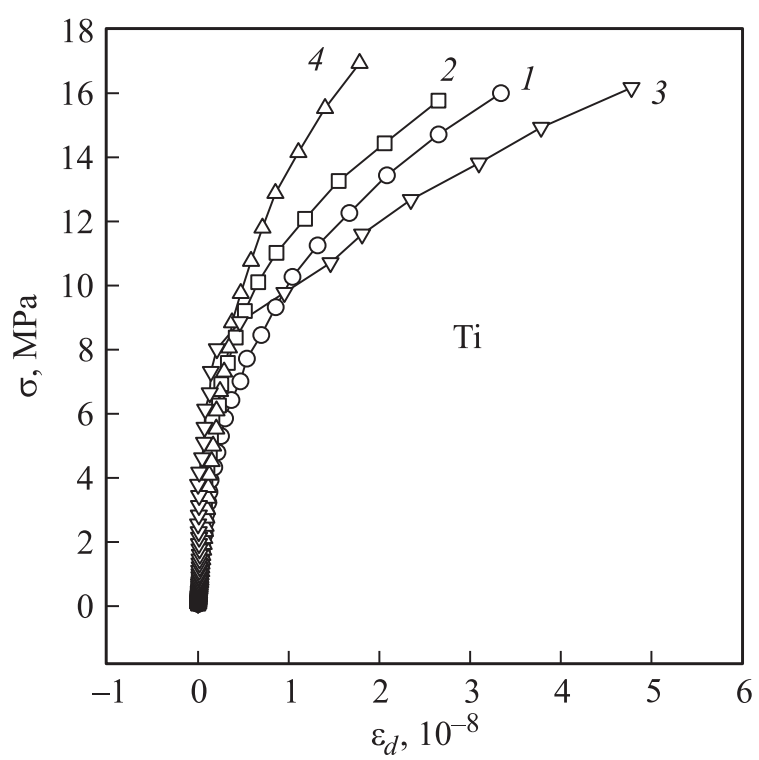

Рис. 6. Диаграммы микропластического деформирования для образцов титана: 1 - крупнозернистого Grade 4, 2 - наноструктурного Grade-4, 3 - крупнозернистого BT1-0, 4 крупнозернистого ПТЗ-В.

Этим объясняются отрицательные значения неупругой деформации $\varepsilon_{d}$ на рис. $7, b$.

На ряде образцов титана (см. таблицу) изучалось влияние высокого (до $1.5 \mathrm{GPa}$ ) гидростатического давления 
Плотность $\rho$, модуль Юнга $E$, амплитудно-независимый декремент $\delta_{i}$, условный предель микротекучести $\sigma_{y}$ при величине неупругой деформации $\varepsilon_{d}=2.0 \cdot 10^{-8}$ для образцов титана BT1-0, Grade 4 и ПТ3-В крупнозернисных (К3), наноструктурированных (НС) состояний и после воздействия гидростатического давления $(+P)$. Измерения выполнены при комнатной температуре

\begin{tabular}{l|c|r|r|c}
\hline \multicolumn{1}{c|}{ Материал } & $\rho, \mathrm{g} / \mathrm{cm}^{3}$ & $E, \mathrm{GPa}$ & $\delta_{i}, 10^{-5}$ & $\sigma_{y}, \mathrm{MPa}$ \\
\hline BT1-0 (К3) & 4.5032 & 108.06 & 94 & 12.0 \\
BT1-0 (К3)+P & 4.5076 & 108.33 & 125 & 10.8 \\
BT1-0 (НС) & 4.6182 & 89.36 & 352 & - \\
BT1-0 (НС)+P & 4.6201 & 86.68 & 401 & - \\
Grade 4 (К3) & 4.5207 & 110.01 & 94 & 13.2 \\
Grade 4 (К3)+P & 4.5228 & 108.30 & 217 & - \\
Grade 4 (НC) & 4.5330 & 108.57 & 100 & 14.2 \\
Grade 4 (НC)+P & - & 108.90 & 150 & 14.0 \\
ПТ3 (К3) & 4.4263 & 118.28 & 96 & 18.0 \\
ПТ3-В (НС) & 4.4350 & 107.79 & 80 & 14.1
\end{tabular}

на упругие и неупругие свойства. Здесь надо отметить, что для крупнозернистого титана ВТ1-0 модуль Юнга слегка увеличивается при слабом увеличении плотности, а для наноструктурированного - модуль, наоборот, уменьшается, а плотность заметно растет. Для титана Grade 4 значительное падение модуля под влиянием давления наблюдается для крупнозернистого состояния, в то время как для наноструктурированного состояния давление незначительно увеличивает модуль. На микропластические свойства (параметр $\sigma_{y}$ в таблице) гидростатическое давление оказывает очень слабое влияние.

\section{Обсуждение}

Изменения модуля упругости и декремента для образцов титана после интенсивной пластической деформации (рис. 3-5) могут быть объяснены следующим образом. Как известно, любая пластическая деформация производит в кристаллическом образце свежие подвижные дислокации, в результате чего модуль упругости, согласно теории, должен уменьшаться и увеличиваться декремент (см., например, $[5,8]$ ).

Однако главная особенность больших деформаций заключается в формировании большого количества мелких зерен [9]. В итоге в поликристаллическом образце появляется повышенная площадь границ. На стыке зерен в образце могут возникать большие внутренние напряжения и появляться различного типа несплошности поры и микротрещины. Такого рода дефекты, как и дислокации, оказывают заметное влияние на упругие и неупругие свойства любых поликристаллических материалов [7].

Влияние пор и микротрещин на модуль Юнга $E$ легко предсказуемо. Ясно, что любая несплошность может только уменьшать действующий модуль упругости. Акустические эксперименты с образцами после приложения
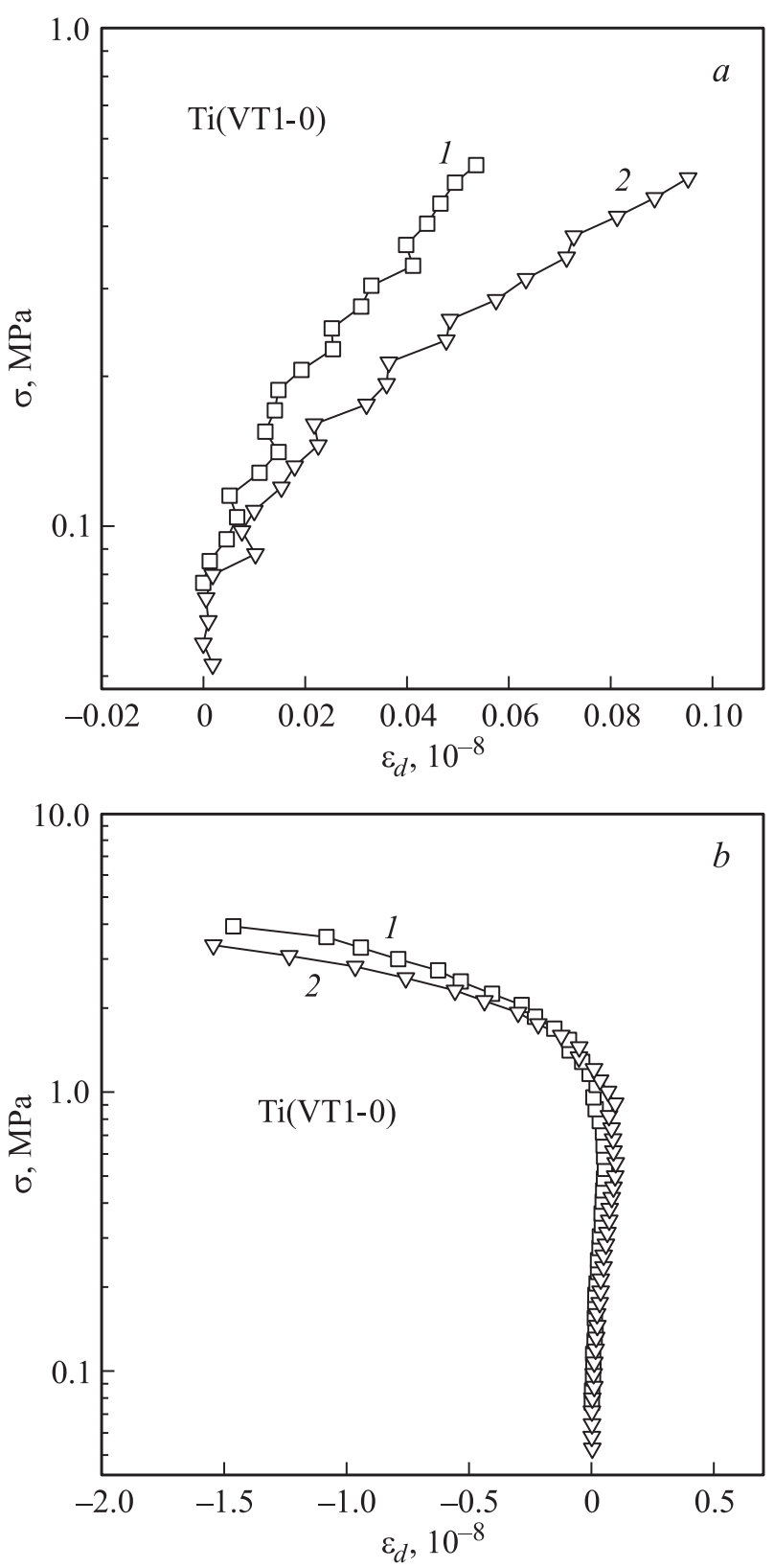

Рис. 7. Диаграммы микропластического деформирования для образцов наноструктурированного титана ВТ1-0 до (1) и после (2) воздействия гидростатического давления.

высокого гидростатического давления должны выявлять заметный рост модуля $E$, если какая-либо несплошность имеется в испытуемом материале. Такого рода эффект давления, небольшой по величине (см. таблицу), для модуля упругости обнаружен у ВТ1-0 (КЗ) и у Grade 4 (HC).

Для ВT1-0 (HC) и Grade 4 (К3) гидростатическое давление, наоборот, привело к уменьшению модуля примерно на $1.5-2 \%$. При этом плотность для ВТ1-0 (НC) заметно увеличилась, что говорит о том, что имеющиеся несплошности в исследованных материалах всетаки залечиваются. Причину такого поведения модуля 
можно приписать либо возникновению дополнительных дислокаций внутри зерен, либо заметному изменению уровня внутренних напряжений. Влияние внутренних напряжений кажется здесь более вероятным. Это связано с тем, что в зернах наноразмеров свободных дислокаций, способных двигаться под действием внешних напряжений, практически нет. Дислокации, если они и возникают, сосредоточиваются вблизи границ зерен и становятся неподвижными.

Измельчение зерен в результате ИПД в настоящей работе выявило еще одну важную деталь: это влияние исходной крупнозернистой структуры на величину модуля упругости титана в наноструктурном состоянии. Необходимо сказать, что титан марки ВТ1-0 с более равноосной крупнозернистой исходной структурой был исследован нами ранее в работе [10]. В этой работе зерна имели начальный размер $\sim(40-50) \mu \mathrm{m}$. В $[10]$ уменьшение модуля Юнга после ИПД составляло от 0.25 до $2.3 \%$ в зависимости от режима прокатки.

В настоящей работе, как упоминалось выше, эффект ИПД для модуля Юнга титана ВТ1-0 оказался на порядок больше - примерно $20 \%$.

Для титанового сплава марки ПТ3-В, также имевшего исходную пластинчатую структуру, эффект ИПД для модуля получился тоже большим $\sim 10 \%$.

Это говорит о том, что исходная структура в этих двух материалах имела решающее значение для величины наблюдаемого эффекта.

Столь значительное влияние на модуль упругости ИПД для пластинчатой исходной структуры можно объяснить, во-первых, дислокациями и изменением уровня внутренних напряжений, во-вторых, возможным появлением текстуры кристаллитов в поликристаллических образцах, формирующейся в результате ИПД.

Роль внутренних напряжений для модуля Юнга, как и влияние дислокаций, по нашим наблюдениям за различными кристаллическими материалами обычно не превышает единиц процентов [7].

Наиболее вероятным объяснением наблюдаемого эффекта остается появление текстуры в зернах - преимущественно одного кристаллографического направления, совпадающего с продольной осью испытуемого образца, после прокатки. Действительно, различия модулей продольной упругости $c_{11}$ и $c_{33}$ для монокристаллического титана при комнатной температуре составляют величину $11.3 \%$, а постоянных $s_{11}$ и $s_{33}-37.3 \%$ [11]. Эти значения по порядку величины совпадают с наблюдаемым эффектом - 20\% для титана ВТ1-0 и 10\% для титанового сплава ПТ3-В.

\section{Заключение}

Анализ результатов, полученных в настоящей работе, показал, что помимо дислокаций, пор, микротрещин и дальнодействующих внутренних напряжений на акустические (упругие и неупругие) свойства поликристалли- ческих материалов может влиять также эффект текстурирования, возникающий после интенсивной пластической деформации в титане с пластинчатой структурой зерна. Процедура получения низкомодульного титана из пластинчатой исходной структуры, по всей видимости, может быть использована для практических применений.

Исследование выполнено за счет гранта Российского научного фонда (проект № 15-12-30010).

\section{Список литературы}

[1] Колобов Ю.Р. // Российские нанотехнологии. 2009. Т. 4. C. $69-81$.

[2] Бетехтин В.И., Колобов Ю.P., Sklenicka V. и др. // ЖТФ. 2015. Т. 85. Вып. 1. С. 66-72.

[3] Москаленко В.А., Бетехтин В.И., Кардашев Б.К. и др. // ФТТ. 2014. Т. 56. Вып. 8. С. 1539-1545.

[4] Бетехтин В.И., Колобов Ю.Р., Голосова О.А. и др. // ЖТФ. 2013. Т. 83. Вып. 10. С. 38-43.

[5] Никаноров С.П., Кардашев Б.К. Упругость и дислокационная неупругость кристаллов. М.: Наука, 1985. 254 с.

[6] Кардашев Б.К. // Кристаллография. 2009. Т. 54. C. $1074-1086$.

[7] Кардашев Б.К., Бетехтин В.И., Нарыкова М.В. // ЖТФ. 2015. Т. 85. Вып. 12. С. 94-106.

[8] Gremaud G. // Mater. Sci. Forum. 2001. Vol. 366-368. P. $178-246$.

[9] Валиев Р.З., Александров Г.В. Наноструктурные металлы, полученные интенсивной пластической деформацией. М: Логос, 2000. 272 c.

[10] Бетехтин В.И., Колобов Ю.Р., Нарыкова М.В и др. // ЖТФ. 2011. Т. 81. Вып. 11. С. 58-63.

[11] Single Crystal Elastic Constants and Calculated Aggregate Properties: a Handbook / Ed. by G. Simmons, H. Wang. The Massachusetts Inst. Technol., 1971. 370 p. 